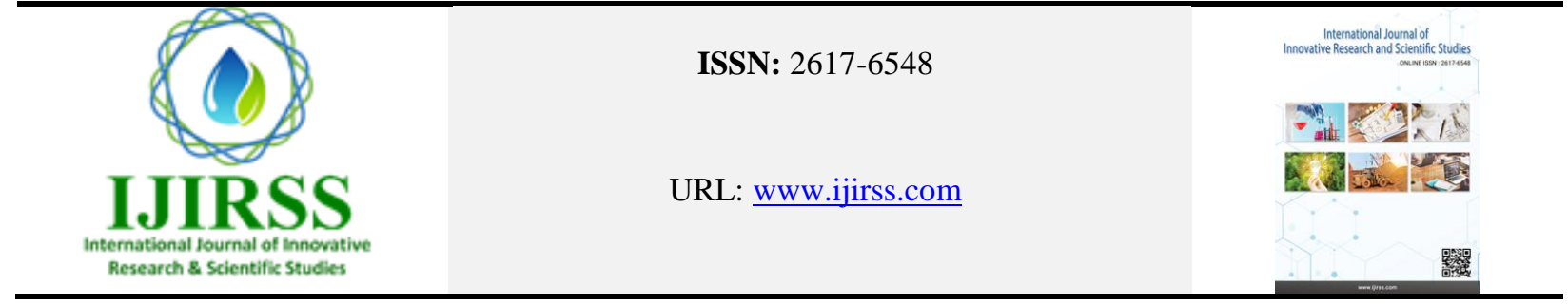

\title{
Assessment of Public Awareness Level Regarding Solid Waste Management: A Case Study of Pol-e-Khumri, Afghanistan
}

\author{
Parwiz Qaderi $^{1 *}$, Misaq Ahmad Muradi², Sayed Abdul Qahar Haqiqat ${ }^{3}$ \\ ${ }^{I}$ Geography Department, Faculty of Education, Baghlan University, Baghlan, Afghanistan. \\ ${ }^{2}$ Civil Engineering Department, Faculty of Engineering, Baghlan University, Baghlan, Afghanistan. \\ ${ }^{3}$ Educational Science Department, Faculty of Education, Baghlan University, Baghlan, Afghanistan. \\ *Corresponding author: Parwiz Qaderi (Jailaniachak11@gmail.com)
}

\begin{abstract}
This study was conducted to assess the awareness level of 786 families regarding solid waste management in Pol-eKhumri. A total of 331 questionnaires were distributed among participants of different educational degrees and age groups from which only 310 questionnaires were returned back. Collected data were analyzed using statistical package for social science (SPSS) software. The results of this research showed that $58 \%$ of participants had weak general awareness regarding solid waste management, while $29 \%$ and $13 \%$ of them had moderate and good awareness level of awareness, respectively. Also, participants had satisfactory level of knowledge about responsible administrations (75\%) and negative impacts of waste dumping (60\%) while, they had moderate level of awareness regarding solid waste management (40\%), waste collection (50\%) and transportation (45\%). Participants showed poor awareness level regarding solid waste disposal methods (25\%), source segregation of waste $(30 \%)$ and hazardous waste $(35 \%)$. The relationship between the demographic characteristics of respondents (sex and level of education) and their general awareness level was also evaluated. It was found that participants with low education degree have less awareness as compared to participants with high degree of education. Study suggests that there must be an integrated program about solid waste management and enhancing public awareness. Short- and long-term educational programs such as discussions, seminars, workshops and preaching in Masjids are considered to be useful in enhancing public awareness level.
\end{abstract}

Keywords: Educational Degree, Educational Programs, Pol-e-Khumri, Public Awareness, Solid Waste.

DOI: $10.53894 /$ ijirss.v4i4.85

Funding: This study received no specific financial support.

History: Received: 19 March 2021/Revised: 3 June 2021/Accepted: 8 July 2021/Published: 23 August 2021

Licensed: This work is licensed under a Creative Commons Attribution 4.0 License $(\mathrm{cc})$ Er

Acknowledgement: The authors express their sincere gratitude to all participants for responding the questions and to the educational institutions for allowing them in questionnaire distribution and data collection.

Competing Interests: The authors declare that they have no conflict of interests.

Transparency: The authors confirm that the manuscript is an honest, accurate, and transparent account of the study was reported; that no vital features of the study have been omitted; and that any discrepancies from the study as planned have been explained.

Ethical: This study follows all ethical practices during writing.

\section{Introduction}

Solid waste control, collection and disposal has become a big problem nowadays. Therefore, solid waste management is among the main concerns of human societies. Increase of waste production from one side and its diversity on the other hand have added to the complexity of how waste is collected and disposed. Developments in science and technology in 
various fields has led to the entry of hazardous waste, even in the household waste [1]. Pol-e-Khumri has a total population of 237888 in 2019 [2]. This number of people has the capacity to generate almost 100 tons of waste per day (Table 1). Municipalities are responsible for waste collection and management as per the Afghanistan's law, but Pol-e-Khumri municipality does not have the ability to collect and manage the solid waste generated due to the limited number of equipment and resources. On the other hand, lack of dustbins, non-existence of routine collection and transport system, absence of standard landfill and less awareness of people regarding solid waste management, and its importance are considered as the major challenges in solid waste management sector of mega cities of Afghanistan [3].

Public participation has its vital impact on solid waste management and this work can be accomplished by increasing the public awareness level through conducting seminars, workshops, short term courses and other alternative methods. Many researchers investigated public awareness among different focus groups. Public awareness about disposal of solid waste and its impact was studied in Thanapara, Beparipara and Kagmari of Tangail Pourashava. The results showed that the service holders, student respondents have better idea about the effects of dumping solid wastes at open sights than the other authorities [4]. Management of municipal solid waste in Kano metropolis, Nigeria, was examined. The study revealed the absence of public awareness and participation, and suggested group discussions and other similar methods to enhance level of awareness amongst the people about the solid waste management [5]. Public awareness, education and participation in solid waste management were studied among a community in Tehran. The results of the study showed that only about onethird of the people had appropriate awareness in the field of solid waste management. The overall status of public education in solid waste management was also insufficient, so that $86 \%$ of people were trained at the level ranging from poor to very poor [6]. The knowledge, attitudes, awareness status and behavior concerning solid waste management among the university first year students were assessed in Universiti Kebangsaan Malaysia. Results showed that the students' knowledge, attitudes, awareness status and behavior concerning solid waste management were moderate and it was recommended to promote attitude change and sustainable environmental practices through educational programs [7]. The knowledge and practice of Yazd people in the management of municipal solid waste was studied. Research clarified that Knowledge of recycling items such as waste paper, cardboard, glass, metals and plastics stands in the rank of moderate to good but performance of the citizens in relation to the municipality is in a weak condition [8,9]. This study was carried out in order to assess the awareness level of Pol-e-Khumri residence regarding solid waste management. Research findings are important for people and the Pol-e-Khumri municipality and Baghlan Environmental Protection Administration. They can plan short and long term programs based on the results of this study for improvement of waste management status. Study will also help people in order to pay more attention to their responsibilities about this important issue.

\section{Materials and Methods}

The method of this research is descriptive and was carried out using self-administered questionnaire. In this study, Likert scale was used. The questionnaire was consisting of 16 items in three parts: 1) personal information (7 items), 2) general awareness (1 item) and 3) awareness based on issues (8 items). Public awareness is the dependent variable while sex, occupation and education degree are the independent variables. Three elder members of 786 families were considered as population size in this research which becomes 2358 persons. The sample size was found 331 from Morgan's table and questionnaires were distributed simple randomly among participants. In order to determine the validity of research, questionnaire was given to five university lecturers and their suggestion were included in the last version of questionnaire. Cronbach's alpha was the measure of reliability in this research and it was found 0.7 for main questions of questionnaire. Data were analyzed after collection using Statistical package for social science (SPSS) software.

\subsection{Study Area}

Pol-e-Khumri is the centre and one of the largest cities of Baghlan province. The city has a population of 237,888 (in 2019). Pol-e-Khumri is considered as a fast growing city in Baghlan. Census data shows an increase of $3 \%$ in the number of people. Unsuitable social and economic conditions pushed the people in rural areas to migrate to Pol-e-Khumri. It has 6 districts and total area of 37.52 kilometre square. As per National solid waste management policy, municipal solid waste generation rate is $0.4 \mathrm{Kg}$ /person/day. Considering this norm and multiplying it with the number of residents, Pol-e-Khumri has the capacity to generate more than 95 tons of waste every day (Table 1). District one is among major waste generators with a total number of 65432 people, while district four has low generation capacity with the total number of 15792 people. The solid waste is generated from different sources such as residential, commercial, industrial and clinical in Pol-e-Khumri but the major part of the waste comes from householders.

Table-1.

Solid waste generation capacity of Pol-e-Khumri.

\begin{tabular}{c|c|c|c|c}
\hline Sr.No & District & Population & SWGR $^{\mathbf{~}}(\mathbf{K g} / \mathbf{p e r s o n} / \mathbf{d a y})$ & TSWG $^{\mathbf{2}}(\mathbf{K g})$ \\
\hline 1 & 1st & 65432 & $0.4^{3}$ & 26173 \\
\hline 2 & 2nd & 48865 & 0.4 & 19546 \\
\hline 3 & 3rd & 20982 & 0.4 & 8393 \\
\hline 4 & 4th & 15792 & 0.4 & 6317 \\
\hline 5 & 5th & 53577 & 0.4 & 21431 \\
\hline 6 & 6th & 33240 & 0.4 & 13296 \\
\hline \multicolumn{2}{c}{ Total 237888} & & 95155 \\
\hline
\end{tabular}

1) Solid waste generation rate 2) Total solid waste generation

3) As per National solid waste management policy [10]. 


\section{Results and Discussion}

The demographic information reveals that among 310 participants, 200 of them $(64.5 \%)$ are male and 110 of them $(35.5 \%)$ are female. 150 participants $(48.4 \%)$ are married, 156 participants $(50.3 \%)$ are single and remaining are widows. Most of the participants (179) are in the age of 20 to 25, and minority of them (24) are in the age of 36 to 40 that makes $57.7 \%$ and $9.0 \%$ of the total participants, respectively. Majority of the participants (137) which makes (44\%) of all respondents were students and minority of them (6\%) were either jobless, shopkeeper or self-employment (Figure 1a). Most of the respondents (34\%) had a bachelor's degree while some of them (1\%) were doctors (Figure 1b).

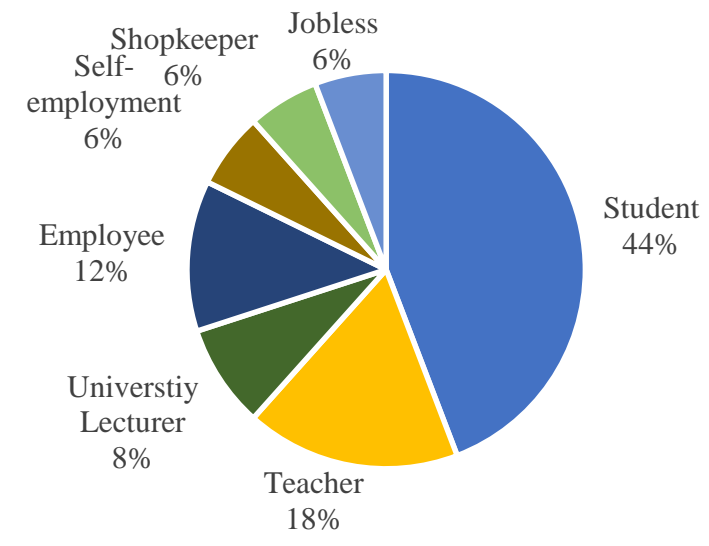

(a)

Figure-1.

(a) Occupation and (b) education degree of participants.

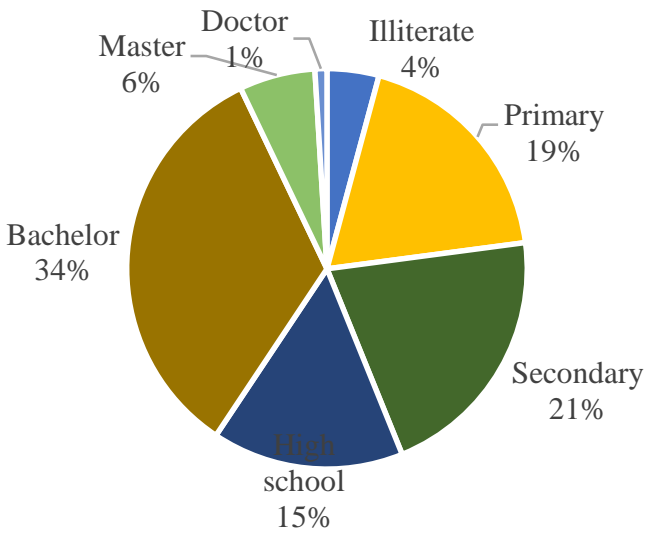

(b)

Data gathered for general awareness of participants (Figure 2a) shows that only $13 \%$ of participants are in good level of awareness. General awareness of $29 \%$ were assessed as moderate and remaining participants, which makes $58 \%$ of them, have weak awareness level. There are many reasons behind participant's low level of awareness, mainly including unsecure situation, 3 decades of war, lack of an integrated program regarding awareness, inactivity of responsible administrations, non-existence of educational programs especially in Medias and many more. Low level of knowledge was found on relevant laws and regulations pertaining to solid waste management among respondents in Al-Nassyriah City, Iraq and most of them were unable to put their limited knowledge into practice [11]. Results also obtained from the study revealed low level of awareness about indiscrimination dumping of waste in Benin City, Nigeria [12].
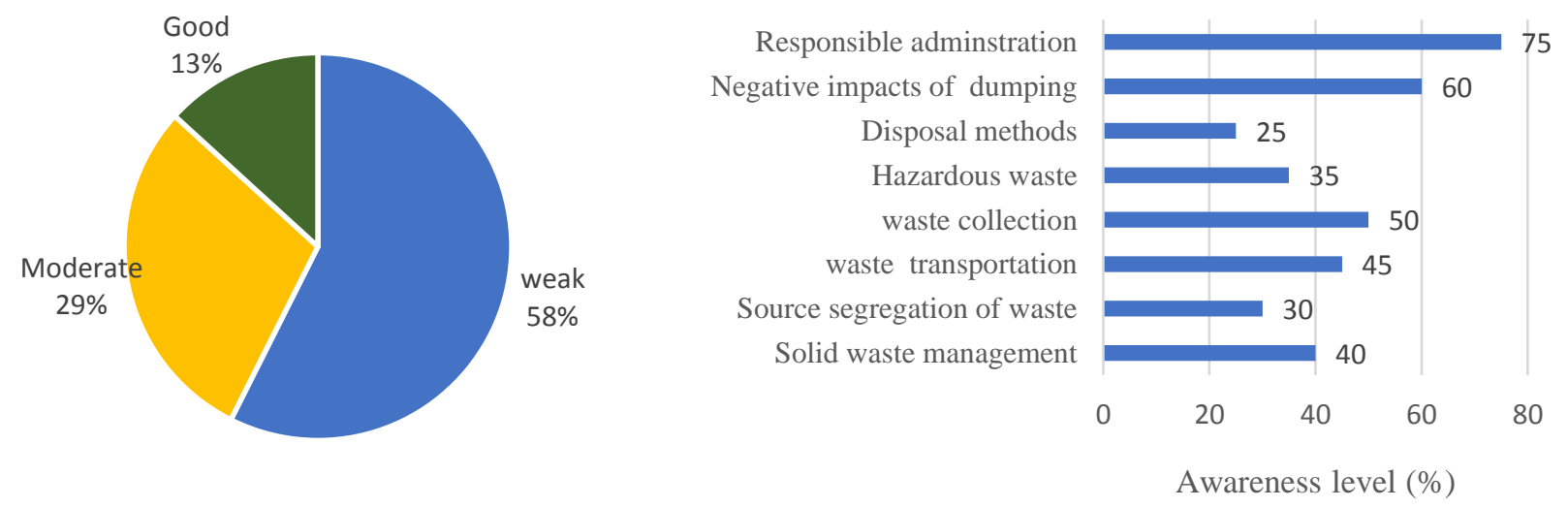

Figure-2.

(a) General awareness and (b)awareness based on issues regarding solid waste management.

The results obtained for awareness based on issues reveals that the awareness level of participants is less than moderate. Figure $2 \mathrm{~b}$ shows that participants have low level of knowledge about disposal methods (25\%), source segregation of waste $(30 \%)$ and hazardous waste $(35 \%)$. At the same time, moderate level of awareness can be seen in solid waste management (40\%), waste collection (50\%) and waste transportation (45\%). Participants have relatively good level of awareness regarding negative impacts of waste dumping (60\%) and responsible administration of solid waste management $(75 \%)$. Although participants have relatively low level of awareness about source segregation, hazardous waste, waste collection and disposal due to non-existence of educational programs, still they have good information regarding responsible administrations. Solid waste dumping has affected people in many ways especially they have been infected to lots of diseases that is the main reason behind their relatively good awareness level in this regard. It is stated in a study that public must made aware about suitable management of waste and the consequences of improper management of 
it and its impacts on human health [13]. It is recommended to include environmental sustainability education in curriculum of schools at all levels in developing countries [14].

Hypothesis1: It seems that there is a relationship between education degree and general awareness of participants regarding solid waste management.

Table-2.

Relation between education degree and general awareness of participants regarding solid waste management.

\begin{tabular}{|c|c|c|c|c|c|c|c|}
\hline & & \multicolumn{5}{|c|}{ General awareness level } & \multirow{2}{*}{ Total } \\
\hline & & Very much & Much & Middle & Less & Very less & \\
\hline \multirow{7}{*}{ Education degree } & Illiterate & 1 & 1 & 2 & 8 & 1 & 13 \\
\hline & Primary & 5 & 11 & 10 & 16 & 16 & 58 \\
\hline & Secondary & 15 & 4 & 9 & 25 & 12 & 65 \\
\hline & High school & 11 & 9 & 9 & 10 & 9 & 48 \\
\hline & Bachelor & 12 & 28 & 24 & 24 & 16 & 104 \\
\hline & Master & 2 & 2 & 3 & 5 & 7 & 19 \\
\hline & Doctor & 3 & 0 & 0 & 0 & 0 & 3 \\
\hline \multicolumn{2}{|l|}{ Total } & 49 & 55 & 57 & 88 & 61 & 310 \\
\hline
\end{tabular}

It's reveled from Table 2 that from a total of 310 respondents, 13 individuals are illiterate and 58 and 65 have studied primary and secondary schools, respectively, 48 graduated from high school, 104 of them had bachelor's degree, 19 of the participants had a master degree and only 3 of them had a PhD. In illiterate degree, 1 (7.7\%) has chosen very much, 1 $(7.7 \%)$ has chosen much, $2(15.4 \%)$ have chosen middle, $8(61.5 \%)$ have chosen less and $1(7.7 \%)$ has chosen very less in general awareness level. Almost same trend can be seen in education degrees such as: primary, secondary and high school. Respondents with high education degrees showed satisfactory awareness level. In bachelor's degree, 12 (11.5\%) have chosen very much, 28 (26.9\%) have chosen much, 24 (23.08\%) have chosen middle, $24(23.08 \%)$ have chosen less and 16 $(15.4 \%)$ have chosen very less in general awareness level. Nearly similar results were obtained for education degrees such as master and Ph.D.

Table-3.

\begin{tabular}{l|c|c|c}
\hline Chi-square Tests. & Value & df & $\begin{array}{c}\text { Asymptotic } \\
\text { Significance (2-sided) }\end{array}$ \\
\hline Pearson Chi-Square & $53.122^{\mathrm{a}}$ & 24 & 0.001 \\
\hline Likelihood Ratio & 47.936 & 24 & 0.003 \\
\hline Linear-by-Linear Association & 3.801 & 1 & 0.051 \\
\hline N of Valid Cases & 310 & & \\
\hline
\end{tabular}

In order to find the relationship between education degree and general awareness of participants, chi-square test was carried out (Table 3). Chi-square test has many applications, for instance, confidence interval estimation, sample variance, test of variance, test of deviations and many more. It also compares two categorical variables (e.g. education degree, awareness level) to see whether they are related. Results from chi-square test showed that with $1 \%$ error, $99 \%$ confidence and 24 degree of freedom the relationship between two above mentioned variables is significant. It is revealed that participants with low education degree have less awareness as compared to participants with high degree of education. This relationship recommends that people with low degree of knowledge and low level of awareness should be in the top of the list of educational programs regarding solid waste management. It is mentionable that by enhancing degree of knowledge, awareness of people will be increased. It was found that people had different levels of knowledge regarding waste generation and collection even they were at the same degree of education in Romania [15].

\section{Conclusion}

This research was conducted in order to assess participants' awareness level in Pol-e-Khumri. A total of 310 questionnaires were returned back and general awareness and awareness based on issues of participants were found. Collected data were analyzed using SPSS software. The main reasons behind low, moderate and relatively good awareness level of participants were clarified. From this research, the following conclusions were drawn:

- Although some of the participants have relatively good general awareness (29\%) regarding solid waste management, most of them are in low (58\%) awareness level category.

- Participants' awareness level is low regarding solid waste disposal methods (25\%), source segregation of waste (30\%) and hazardous waste $(35 \%)$.

- Level of awareness of participants was assessed as relatively moderate about solid waste management (40\%), waste collection $(50 \%)$ and transportation $(45 \%)$. 
- Relatively good awareness of participants was observed in negative impacts of solid waste dumping (60\%) and responsible administrations (75\%).

- Results from chi-square test shows that with $1 \%$ error and $99 \%$ confidence, there is a relationship between education degree and general awareness of participants. It reveals that participants with low degree of education have less awareness as compared to participants with high degree of education.

- This study suggests that responsible administrations especially Pol-e-Khumri municipality and Baghlan Environmental protection department must plan integrated programs for solid waste management in a good manner and enhancing public awareness.

- Short and long term educational programs must be launched by responsible administrations and local Medias. Some of the methods that can be effective are face to face discussion with householders, seminars and workshops, short films or videos from local televisions, delivering some special messages regarding solid waste management by preachers in Masjids, placing educational brochures in suitable areas and many more.

\section{References}

[1] H. Zolfeqari, Principles of enironment, 1st ed. Kermanshah: Razi University, 2008.

Afghanistan-Statistical-Yearbook-2018-19_Compressed, 2018.

[3] P. Qaderi, Development of waste management practices for mega cities (Kabul City): Kazakh National Research Technical University, 2015.

[4] B. Sarker, S. Sarker, M. Islam, M. Islam, and S. Sharmin, "Public awareness about disposal of solid waste and its impact: A study in Tangail Pourashava, Tangail," Journal of Environmental Science and Natural Resources, vol. 5, pp. 239-244, 2013.Available at: https://doi.org/10.3329/jesnr.v5i2.14821.

[5] B. Draszawka, "Bołzan world scientific news," World Sci. News, vol. 5 pp. $26-34,2014$.

[6] M. Abtahi, R. Saeedi, M. N. Boroojerdi, A. Fakhraeefar, A. Bayat, F. Aliasgari, and M. Alizadeh, "Public awareness, education and participation in solid waste management in Tehran," Journal of Health in the Field, vol. 3, pp. 7-16, 2015.

[7] A. Desa, N. Ba'yah Abd Kadir, and F. Yusooff, "Waste education and awareness strategy: towards solid waste management (SWM) program at UKM," Procedia-Social and Behavioral Sciences, vol. 59, pp. 47-50, 2012.Available at: https://doi.org/10.1016/j.sbspro.2012.09.244.

[8] S. O. Iheukwumere, K. F. Nkwocha, and C. P. Nwabudike, "Schematic modelling of sustainable solid waste management in Nigeria," International Journal of Sustainable Energy and Environmental Research, vol. 9, pp. 98-109, 2020.Available at: https://doi.org/10.18488/journal.13.2020.92.98.109.

[9] A. Ebrahimi, M. Ehrampoosh, M. Samaei, E. Shahsavani, Y. Afra, and M. Abotorabi, "Survey of knowledge and practice of Yazd people regarding municipal solid waste management in 2008," J. Med. Sci. Yazd., vol. 4, pp. 80-90, 2010.

[10] N. E. P. Agency, "National policy of solid waste management," 2010.

[11] M. J. A. Hasan, M. M. Hanafiah, and M. S. Satchet, "Public awareness on solid waste management: A case study in AlNassyriah City, Iraq," in AIP Conference Proceedings, 2019, p. 060013.

[12] P. O. Adekola, F. O. Iyalomhe, A. Paczoski, S. Abebe, B. Pawłowska, M. Bąk, and G. Cirella, "Public perception and awareness of waste management from Benin City," Scientific Reports, vol. 11, pp. 1-14, 2021.Available at: https://doi.org/10.1038/s41598-020-79688-y.

[13] S. Hasan, "Public awareness is key to successful waste management," Journal of Environmental Science and Health, Part A, vol. 39, pp. 483-492, 2004.Available at: https://doi.org/10.1081/ese-120027539.

[14] I. A. Al-Khatib, H. A. Arafat, T. Basheer, H. Shawahneh, A. Salahat, J. Eid, and W. Ali, "Trends and problems of solid waste management in developing countries: A case study in seven Palestinian districts," Waste Management, vol. 27, pp. 1910-1919, 2007.Available at: https://doi.org/10.1016/j.wasman.2006.11.006.

[15] F. Morar and B. Bucur, "Raising awareness on waste generation and collection," Procedia Engineering, vol. 181, pp. 452-458, 2017.Available at: https://doi.org/10.1016/j.proeng.2017.02.415. 